in place of the old medical outpatient system. Where medical input was required, advice could be sought from the hub doctor and patients could be seen in the new ambulatory clinic or at home as needed. Of 21 patients were referred for hospice inpatient admission, 18 were admitted within 1 day, an improvement on the 2019-2020 average time from referral to admission of 3 working days. Of 26 patients triaged for medical outpatient review 23 were reviewed within 24 hours (8 same day) $\hat{a} €$ ' the previous average was 15 working days from referral to appointment.

Conclusions The switch to a daily ambulatory clinic has improved timeliness of medical assessment and domiciliary visits have been completed in a more timely manner due to freeing up medical availability. Co-location of team members has enhanced information sharing and transfer of care between settings. Patients, carers and staff have reported the benefits of reduced waiting times for specialist input across the services.

\section{QUALITATIVE ANALYSIS OF RECOMMENDED SUMMARY PLAN FOR EMERGENCY CARE AND TREATMENT (RESPECT) WITHIN THE MEDICINE OF THE ELDERLY (MOE) DIRECTORATE AT THE WESTERN GENERAL HOSPITAL}

Katie Robinson, Joanne Mackie, Sarah Keir. NHS Lothian

\subsection{6/spcare-2021-PCC.124}

Background There has been increasing awareness of the value of high-quality anticipatory care planning (ACP) in the frail, elderly population. ACP offers patients with chronic conditions the opportunity to plan their future care and treatment, while they have capacity to do so. This personalised approach improves patient outcomes, particularly towards the end of life. In NHS Lothian there is an opportunity to create a standardised tool to record a patient's ACP decisions. ReSPECT is in use as an ACP form across England and Scotland. ReSPECT focuses on patient wishes and realistic treatment goals prior to an emergency situation when they cannot make or express choices. This project aimed to ascertain whether ReSPECT is a suitable ACP form for a frail, elderly inpatient population in NHS Lothian.

Methods Ten medically stable MOE inpatients were approached for a discussion about their health and future wishes using the ReSPECT form. A questionnaire was created to facilitate this discussion and record responses.

Results Eight of ten participants were happy to discuss future wishes. Four participants found the discussion useful. Two participants found it distressing. Only two participants found the form easy to use.

Conclusions While some participants did find ACP discussions useful, the ReSPECT form was not well received amongst this inpatient sample. Barriers included difficulty understanding the form, concern that wishes were documented irreversibly, and a desire to avoid difficult topics while recovering from acute illness.

In view of the barriers identified, it is clear that we must factor in both sufficient time and support to facilitate patientcentred ACP discussion. In line with patient feedback, it is likely that the best time to initiate this process is not following an acute illness, but when the person is in a period of stability. ReSPECT may be more well received if initiated in primary care.

\section{A SERVICE EVALUATION OF A NEW POLICY TO SUPPORT CARERS GIVING SUBCUTANEOUS ANTICIPATORY MEDICATIONS AT HOME AT END OF LIFE WITHIN SOUTHERN DERBYSHIRE, POPULATION OF 607,000}

Mary Lewis, Jonjo Heneghan, Joseph Burdon. Nightingale Macmillan Unit, Royal Derby Hospital

\subsection{6/spcare-2021-PCC.125}

Background The Derbyshire Policy for Informal Carers Administration of as required Subcutaneous Injections in Community Palliative Care was developed by Specialist Palliative Care Services, in conjunction with multiple agencies across Derbyshire. During policy development, for governance and learning, it was agreed that a rolling service evaluation would be undertaken and learning fed back to community partners annually.

Methods A qualitative acceptability question was posed to the caregiver after the relative had died. 'Was the process acceptable and beneficial?'

Demographic and quantitative data was collected at time of death.

- Number of injections of each drug given was collated from stock balance charts in the patient's home and correlated with the call $\log$.

- Number of days carer enabled to give anticipatory drugs.

All carers were trained by the same palliative care consultant and supported by a designated community palliative care nurse. To support carers, a telephone call to specialist palliative care was mandated prior to each injection being given by the carer.

Results Six carers were trained between March and September 2020. Five have a health professional background. Four were trained at home and two in the Specialist Palliative Care Unit. Qualitative data is available for four patients who have died. The number of injections of anticipatory medications given by carers varies.

Patient 1: 109 injections over a 137 day period of care

Patient 2: 9 injections over a 7 day period of care

Patient 3: 2 injections over a 6 day period of care

Patient 4: 41 injections over a 16 day period of care

The breakdown of which drugs were given is available. All 4 relatives of deceased patients felt that the training was acceptable.

Conclusions Training carers to give subcutaneous anticipatory medications at home is acceptable and enables drug administration. The policy is available at https://derbyshire.eolcare.uk/ content/documents/uploads/tollkit-docs/POLICY-FOR-SC-

ADMINISTRATION.pdf

\section{A STUDY TO EXPLORE HOSPICE CATERING STAFF'S EXPERIENCES WITH PALLIATIVE AND DYING PATIENTS}

Rebecca Darge, Stephen Cox, Charlotte Brigden, Andrew Thorns. Pilgrims Hospices

\subsection{6/spcare-2021-PCC.126}

Background It is recognised that clinical staff in various specialities engage with the ideas of death and dying. Less recognition is given to the experiences of non-clinical staff in contact with palliative patients. We identified Jors (2017) 